\title{
О ПРАКТИКЕ НАЗНАЧЕНИЯ АДМИНИСТРАТИВНОГО ШТРАФА ЗА ПРАВОНАРУШЕНИЯ В ОБЛАСТИ ТАМОЖЕННОГО ДЕЛА
}

A дминистративный штраф является самым распространенным видом административных наказаний в области таможенного дела и предусмотрен в качестве единственной либо альтернативной меры ответственности за каждое из правонарушений, содержащихся в главе 16 Кодекса Российской Федерации об административных правонарушениях (далее КоАП РФ). Согласно данным ведомственной статистики Федеральной таможенной службы, из числа лиц, привлеченных к административной ответственности за нарушение таможенных правил в 2012 году, 72,6 \% правонарушителей назначено наказание в виде административного штрафа ${ }^{1}$.

В санкциях 35 составов правонарушений размер административного штрафа установлен в твердой денежной сумме (в рублях), еще в 7 случаях величина штрафа кратна стоимости товаров и (или) транспортных средств, явившихся предметами (орудием) правонарушения, в 1 случае - сумме неуплаченных или подлежащих уплате таможенных пошлин и налогов, еще в 1 - незадекларированной сумме наличных денежных средств или стоимости денежных инструментов.

С момента вступления в силу действующего КоАП РФ в 2001 году на протяжении практически 10 лет под понятием «стоимость товаров, явившихся предметами административного правонарушения» понималась их рыночная стоимость, для определения которой в рамках производства по делам об административных правонарушениях таможенными органами назначались товароведческие стоимостные экспертизы. Стоимость товаров, указанная экспертом, и использовалась в качестве основы для исчисления размеров административных штрафов, налагаемых на правонарушителей.

Однако 13 июля 2010 года Конституционным Судом Российской Федерации принято Постановление

1 См.: Итоги правоохранительной деятельности таможенных органов Российской Федерации за 2012 год [Электронный ресурс] / Федеральная таможенная служба. Режим доступа: http://customs.ru/index. php?option $=$ com content $\&$ view $=$ article $\&$ id $=16960$ :-2012\&catid $=55: 2011-01-24-16-40-26$
№ 15П, которым признаны не соответствующими Конституции РФ положения ч. 1 ст. 16.2 и ч. 2 ст. 27.11 КоАП РФ, предусматривающие в их взаимосвязи при оценке стоимости товара, перемещаемого физическим лицом через таможенную границу и предназначенного для личного пользования, в целях исчисления административного штрафа использование его рыночной стоимости на территории России и включение в стоимость товара для указанных целей той его части, которая разрешена к ввозу без письменного декларирования и уплаты таможенных пошлин. Данное решение мотивировано тем, что физические лица, приобретая товары на территории иностранных государств и не располагая сведениями об их рыночной стоимости в России (которая, будучи определенной экспертным путем, может различаться в зависимости от применяемых методик и региона, в котором проводится экспертиза), не имеют возможности предвидеть правовые последствия своего поведения, что при привлечении их к ответственности приводит к нарушению конституционных принципов справедливости и равенства².

В последующем Конституционным Судом РФ вынесено еще одно постановление (от 26 ноября 2012 года № 26П), в котором уточнено, что указанная правовая позиция не может в полной мере распространять свое действие на юридических лиц, поскольку, в силу особого правового статуса последних, законодатель полномочен устанавливать для них повышенный объем административной ответственности за совершение аналогичных противоправных деяний ${ }^{3}$. Этим же поста-

2 См.: Постановление Конституционного Суда РФ от 13.07.2010 № 15-П «По делу о проверке конституционности положений части первой статьи 188 Уголовного кодекса Российской Федерации, части 4 статьи 4.5, части 1 статьи 16.2 и части 2 статьи 27.11 Кодекса Российской Федерации об административных правонарушениях в связи с жалобами граждан В.В. Баталова, Л.Н. Валуевой, З.Я. Ганиевой, О.А. Красной и И.В. Эпова // Собрание законодательства Российской Федерации. 2010. № 29. Ст. 3983.

3 См.: Постановление Конституционного Суда РФ от 26.11.2012 № 28-П «По делу о проверке конституционно- 
новлением законодателю предписано внести изменения в КоАП РФ, определив вид стоимости, используемой для исчисления административного штрафа за недекларирование товаров (ч. 1 ст. 16.2 КоАП РФ).

Федеральным законом РФ от 30 декабря 2012 года № 316-Ф3 в КоАП РФ внесены изменения, детализирующие порядок определения стоимости предметов правонарушений. Так, статья 16.2 дополнена примечанием, согласно которому для исчисления размера административного штрафа за недекларирование товаров, налагаемого на граждан, используется стоимость товаров для личного пользования, перемещаемых физическими лицами через таможенную границу, из которой вычитается стоимость товаров, разрешенных к перемещению без уплаты таможенных платежей. Часть 2 статьи 27.11 изложена в новой редакции, согласно которой стоимость изъятых вещей, в отношении которых не установлены государственные регулируемые цены, должна определяться на основании их рыночной стоимости, а изъятых товаров для личного пользования, перемещенных физическими лицами, на основании их таможенной стоимости, исчисленной в соответствии с главой 49 Таможенного кодекса Таможенного союза (ТК ТС).

Произведенные изменения оказали значительное влияние на практику назначения административных наказаний в виде административного штрафа. Анализ постановлений судов и таможенных органов по делам об административных правонарушениях показывает, что в настоящее время под понятием «стоимость товаров, явившихся предметами административного правонарушения» понимается:

- при недекларировании физическими лицами товаров для личного пользования - их таможенная стоимость;

- в иных случаях - рыночная стоимость товаров, перемещаемых через таможенную границу.

Однако предписанная Конституционным Судом РФ и впоследствии закрепленная в законе дифференциация размеров административного наказания в зависимости от категории субъекта, привлекаемого к ответственности, на практике приводит к неоднозначному толкованию положений КоАП РФ.

Прежде всего, необходимо отметить, что Конституционный Суд РФ, признавая неконституционной часть

сти положений части 1 статьи 16.2 и части 2 статьи 27.11 Кодекса Российской Федерации об административных правонарушениях в связи с жалобой общества с ограниченной ответственностью «Авеста» // Собрание законодательства Российской Федерации. 2012. № 50 (ч. 6). Ст. 7124.
1 статьи 16.2 КоАП РФ, подчеркивал, что данная норма вообще не содержит указаний на вид стоимости, применяемой при исчислении административного штрафа. В свою очередь, статья 27.11 КоАП РФ устанавливала необходимость расчета рыночной стоимости исключительно в отношении изъятых товаров, тогда как данная мера обеспечения производства в рамках конкретного дела может и не применяться.

Изменения, внесенные Федеральным законом РФ от 30 декабря 2012 года № 316Ф3, не устранили данный пробел: примечание к статье 16.2 КоАП РФ по-прежнему содержит понятие «стоимость», не указывая ее вид.

Тем не менее, положения части 2 статьи 27.11 КоАП РФ по-прежнему используются судами и таможенными органами во всех случаях при определении величины административного штрафа за недекларирование товаров, несмотря на то, что подобная аналогия закона ранее признана неконституционной.

Как следует из постановлений таможенных органов, в качестве основы для исчисления административного штрафа таможенная стоимость используется только при назначении наказания физическим лицам, перемещающим товары для личного пользования.

Понятие таможенной стоимости установлено нормами таможенного законодательства Таможенного союза. При этом специфика данного понятия заключается не только в сущности таможенной стоимости как ценовой величины, используемой исключительно для таможенных целей, но и в особой процедуре ее расчета. Определение таможенной стоимости - это таможенная операция, которая может быть совершена либо декларантом при заявлении сведений о товарах, либо уполномоченными должностными лицами таможенных органов при осуществлении таможенного контроля в пределах имеющихся полномочий. В обоих случаях конечным результатом проверки таможенным органом правильности исчисления таможенной стоимости является решение о ее принятии.

Как следствие, расчет величины таможенной стоимости, в том числе для целей привлечения к административной ответственности, может быть произведен исключительно должностными лицами таможенного органа, что делает необоснованным обращение субъектов административной юрисдикции в экспертные учреждения в целях расчета таможенной стоимости товаров. Поэтому на этапе рассмотрения дела оценка в порядке статьи 26.11 КоАП РФ представленных таможенным органом расчетов таможенной стоимости товаров существенно ограничена: даже признав такой расчет недопустимым доказательством, судья либо должностное лицо, рассматривающее дело, пол- 
номочны лишь обратиться с повторным запросом об исчислении величины таможенной стоимости предметов правонарушения в тот же таможенный орган.

Помимо этого, необходимо отметить, что обстоятельства перемещения товаров через таможенную границу могут быть различны.

Так, в случае с гражданами, заявления которых послужили основанием для вынесения Конституционным Судом РФ Постановления от 13 июля 2010 года № 15П, в распоряжении таможенных органов имелись документы, подтверждающие затраты декларанта на приобретение иностранных товаров. Однако практика выявления правонарушений, совершаемых физическими лицами, показывает, что так бывает далеко не всегда. Большинство физических лиц попросту не сохраняет товарные чеки на приобретенные за рубежом товары. Как следствие, их таможенная стоимость может быть вычислена только с использованием имеющихся в распоряжении таможенных органов иных источников ценовой информации. В условиях единичности ввозимых товаров (и отсутствия сведений о каталожных ценах, а также о стоимости идентичных и однородных товаров), таможенная стоимость рассматриваемых товаров, как правило, определяется путем вычитания сумм таможенных пошлин и налогов из их свободной рыночной стоимости в России, которая определена экспертным путем. Анализ решений судов различных регионов подтверждает обоснованность применяемого таможенными органами подхода 4 .

При таких обстоятельствах, к отмеченному в Постановлении Конституционного Суда РФ от 13 июля 2010 года № 15П несовершенству процедуры оценки рыночной стоимости товаров экспертом прибавляется непрозрачность процесса определения таможенной стоимости не задекларированных товаров ввиду различия применяемых методик ее определения 5 , что создает еще большую неясность для правонарушителей.

Согласно постановлению Конституционного Суда РФ от 26 ноября 2012 года № 28-П возможность применения более высоких штрафных административных

\footnotetext{
${ }^{4}$ См., напр.: Постановление Московского городского суда от 13.12.2012 № 4a-2820/12 // Электронный ресурс. - СПС «Консультант Плюс»; Решение Ленинградского областного суда от 15.11.2011 № 7-848/2011 // Электронный ресурс. СПС «Консультант Плюс».

${ }^{5}$ См.: Сидоров Е.И., Хомяков Л.Л. Правовая характеристика и особенности применения административных наказаний за нарушение таможенных правил // Вестник Российской таможенной академии. 2013. №. 2. С. 22.
}

санкций к юридическим лицам, устанавливающая для них повышенную ответственность за нарушения таможенных правил, не противоречит Конституции РФ. Следуя указанной позиции, законодатель фактически закрепил дифференцированную ответственность по части 1 статьи 16.2 КоАП РФ: если для физических лиц административный штраф исчисляется в величине, кратной таможенной стоимости товаров, то для юридических лиц за основу должна по-прежнему браться рыночная стоимость. Таким образом, на первый взгляд, физические лица поставлены в более привилегированное положение в сравнении с организациями, осуществляющими внешнеэкономическую деятельность на профессиональной основе.

Однако практика привлечения к административной ответственности показывает, что данное обстоятельство весьма неочевидно.

Так, физическими лицами зачастую ввозятся на таможенную территорию товары, отсутствующие в свободной продаже в России. При этом закупочная цена таких товаров может в несколько раз превышать свободную рыночную стоимость аналогичных товаров в России в силу, например, высокой ценности торговой марки ввозимых товаров в стране приобретения (или иных обстоятельств, не влияющих на рыночную цену товаров в России). При таких обстоятельствах таможенная стоимость предметов правонарушения, за основу исчисления которой взята цена товаров в иностранном государстве, может превосходить их рыночную стоимость.

К примеру, в рамках производства по делу об административном правонарушении № 10714000685/2012, в связи с отсутствием документов, подтверждающих стоимость незадекларированных физическим лицом товаров, Находкинской таможней назначена экспертиза по определению рыночной стоимости предметов правонарушения. Согласно заключению эксперта, стоимость товаров на открытом рынке в России составила порядка 3000 рублей.

Вместе с тем, в последующем лицом, привлекаемым к ответственности, в таможенный орган представлены товарные чеки, подтверждающие стоимость приобретения незадекларированных предметов за рубежом. Согласно указанным документам, закупочная цена товаров в рублевом эквиваленте превышает 22600 рублей. Учитывая, что в соответствии с требованиями ст. 361 Таможенного кодекса Таможенного союза использование собственной информации таможенного органа в целях расчета таможенной стоимости товаров для личного пользования возможно только при отсутствии оригиналов документов, подтверждающих их цену в стране приобретения, в рассматрива- 
емом случае при расчете стоимости предмета правонарушения использована действительная стоимость товаров, превышающая рыночную более чем в 6 раз.

Таким образом, сложившаяся ситуация, при которой для разных категорий субъектов административной ответственности установлены различные виды стоимости, используемой для исчисления административных штрафов, порождает множество противоречий. При этом необходимо также учитывать, что неодинаковый объем ответственности и, как следствие, различные риски при выявлении совершенных правонарушений способствует возникновению ситуации, при которой недобросовестные участники внешнеэкономической деятельности могут использовать подставных физических лиц в качестве номинальных приобретателей товаров, которые предполагается ввезти на таможенную территорию без декларирования по установленной форме. В этом случае минимизация рисков привлечения к ответственности в случае перемещения таких товаров от имени физических лиц может послужить условием к активизации противоправной деятельности в таможенной сфере.

При таких условиях представляется необходимым совершенствование системы наказаний в области таможенного дела на основе единых подходов к определению стоимости предметов правонарушений для целей исчисления административного штрафа вне зависимости от категории субъекта, привлекаемого к ответственности за недекларирование товаров.

В этой связи, по мнению автора, с учетом позиции Конституционного Суда РФ, таможенная стоимость товаров может быть использована в качестве основы для исчисления административного штрафа, налагаемого по ч. 1, 2 ст. 16.1 и ч. 1 ст. 16.2 КоАП РФ, лишь при представлении декларантом документов, подтверждающих его затраты на приобретение товаров. В остальных случаях следует использовать рыночную стоимость указанных товаров.

Bce иные нарушения таможенных правил, не связанные с недекларированием товаров и влекущие в качестве наказания административный штраф, крат- ный стоимости предметов правонарушения (ч. 2 ст. 16.18 , ч. 2 ст. 16.19 , ч. 1 ст. 16.20, ст. 16.21 КоАП РФ), представляют собой несоблюдение требований таможенного законодательства в отношении товаров, на которые наложены ограничения. В результате товары, ранее задекларированные таможенному органу с освобождением от уплаты таможенных пошлин и налогов, фактически попадают в свободное обращение. Как следствие, поскольку стоимость предметов правонарушений рассматриваемой категории уже определена при их декларировании, установление их рыночной стоимости в рамках производства по делу об административном правонарушении, с учетом ранее изложенных доводов, представляется излишним.

С учетом изложенного, в целях обеспечения единообразной практики исчисления сумм административных штрафов за правонарушения в области таможенного дела видится целесообразным внести изменения в положения главы 16 КоАП РФ, нормативно определив «стоимость товаров, явившихся предметами административного правонарушения» следующим образом:

«Под понятием «стоимость товаров, явившихся предметами административного правонарушения» понимается таможенная стоимость, принятая при декларировании данных товаров в связи с их перемещением через таможенную границу. Если товары, явившиеся предметами административного правонарушения, не задекларированы таможенному органу, под понятием «стоимость товаров, явившихся предметами административного правонарушения» понимается их таможенная стоимость, определенная на основании представленных декларантом коммерческих документов, а при их отсутствии (а равно если такие документы не представлены либо не могут быть соотнесены с товарами) - рыночная стоимость, определенная на основании заключения эксперта».

\section{Библиография}

1. Итоги правоохранительной деятельности таможенных органов Российской Федерации за 2012 год [Электронный ресурс] / Федеральная таможенная служба. Режим доступа: http://customs.ru/index.php?option=com_ content\&view=article\&id=16960:-2012-\&catid=55:2011-01-24-16-40-26

2. Постановление Конституционного Суда РФ от 13.07.2010 № 15-П «По делу о проверке конституционности положений части первой статьи 188 Уголовного кодекса Российской Федерации, части 4 статьи 4.5, части 1 статьи 16.2 и части 2 статьи 27.11 Кодекса Российской Федерации об административных правонарушениях в связи с жалобами граждан В.В. Баталова, Л.Н. Валуевой, З.Я. Ганиевой, О.А. Красной и И.В. Эпова // Собрание законодательства Российской Федерации. 2010. № 29. Ст. 3983.

3. Постановление Конституционного Суда РФ от 26.11.2012 № 28-П «По делу о проверке конституционности 
положений части 1 статьи 16.2 и части 2 статьи 27.11 Кодекса Российской Федерации об административных правонарушениях в связи с жалобой общества с ограниченной ответственностью «Авеста» // Собрание законодательства Российской Федерации. 2012. № 50 (ч. 6). Ст. 7124.

4. Постановление Московского городского суда от 13.12.2012 № 4a-2820/12 // Электронный ресурс. - СПС «Консультант Плюс».

5. Решение Ленинградского областного суда от 15.11.2011 № 7-848/2011 // Электронный ресурс. - СПС «Консультант Плюс».

6. Сидоров Е.И., Хомяков Л.Л. Правовая характеристика и особенности применения административных наказаний за нарушение таможенных правил // Вестник Российской таможенной академии. 2013. №. 2. С. 20-26.

7. Куракин А.В., Бадулин А.Д., Трегубова Е.В. Административная ответственность за правонарушения на рынке алкоголя и роль полиции в ее реализации // NB: Административное право и практика администрирования. - 2013. - 10. - C. 28 - 74. URL: http://www.e-notabene.ru/al/article_10151.html

\section{References (transliteration):}

1. Itogi pravookhranitel'noi deyatel'nosti tamozhennykh organov Rossiiskoi Federatsii za 2012 god [Elektronnyi resurs] / Federal'naya tamozhennaya sluzhba. Rezhim dostupa: http://customs.ru/index.php?option=com_ content\&view=article\&id=16960:-2012-\&catid=55:2011-01-24-16-40-26

2. Postanovlenie Konstitutsionnogo Suda RF ot 13.07.2010 № 15-P «Po delu o proverke konstitutsionnosti polozhenii chasti pervoi stat' $i 188$ Ugolovnogo kodeksa Rossiiskoi Federatsii, chasti 4 stat' $i 4.5$, chasti 1 stat' $i 16.2$ i chasti 2 stat' $i$ 27.11 Kodeksa Rossiiskoi Federatsii ob administrativnykh pravonarusheniyakh v svyazi s zhalobami grazhdan V.V. Batalova, L.N. Valuevoi, Z.Ya. Ganievoi, O.A. Krasnoi i I.V. Epova // Sobranie zakonodatel'stva Rossiiskoi Federatsii. 2010. № 29. St. 3983.

3. Postanovlenie Konstitutsionnogo Suda RF ot 26.11.2012 № 28-P «Po delu o proverke konstitutsionnosti polozhenii chasti 1 stat'i 16.2 i chasti 2 stat'i 27.11 Kodeksa Rossiiskoi Federatsii ob administrativnykh pravonarusheniyakh v svyazi s zhaloboi obshchestva s ogranichennoi otvetstvennost'yu «Avesta» // Sobranie zakonodatel'stva Rossiiskoi Federatsii. 2012. № 50 (ch. 6). St. 7124.

4. Postanovlenie Moskovskogo gorodskogo suda ot 13.12.2012 № 4a-2820/12 // Elektronnyi resurs. - SPS «Konsul'tant Plyus».

5. Reshenie Leningradskogo oblastnogo suda ot 15.11.2011 № 7-848/2011 // Elektronnyi resurs. - SPS «Konsul'tant Plyus».

6. Sidorov E.I., Khomyakov L.L. Pravovaya kharakteristika i osobennosti primeneniya administrativnykh nakazanii za narushenie tamozhennykh pravil // Vestnik Rossiiskoi tamozhennoi akademii. 2013. №. 2. S. 20-26.

7. Kurakin A.V., Badulin A.D., Tregubova E.V. Administrativnaya otvetstvennost' za pravonarusheniya na rynke alkogolya i rol' politsii v ee realizatsii // NB: Administrativnoe pravo i praktika administrirovaniya. - 2013. - 10. - C. 28 - 74. URL: http://www.e-notabene.ru/al/article_10151.html 